Cómo citar en APA: Mayor Tamayo. Jhon Fredy y Alejandro Olaya A. (2021). La eclesiología del Concilio Vaticano ll y de las conferencias generales del Episcopado Latinoamericano en los planes y las prácticas pastorales de la Arquidiócesis de Cali. Cuestiones Teológicas, 48 (110), 343-366. doi:

http://doi.org/10.18566/cueteo.v48n110.a09

Fecha de recepción: 09.06.2021 / Fecha de aceptación: 20.10.2021

\title{
LA ECLESIOLOGÍA DEL CONCILIO VATICANO II Y DE LAS CONFERENCIAS GENERALES DEL EPISCOPADO LATINOAMERICANO EN LOS PLANES Y LAS PRÁCTICAS PASTORALES DE LA ARQUIDIÓCESIS DE CALI
}

\begin{abstract}
The ecclesiology of the Second Vatican Vouncil and of the general conferences of the Latin american Episcopate in the pastoral plans and practices of the Archdiocese of Cali
\end{abstract}

Jhon Fredy Mayor Tamayo ${ }^{\mathrm{I}}$

Alejandro Olaya A. ${ }^{2}$ (iD

\section{Resumen}

Con ocasión del proyecto de investigación "La Sagrada Escritura en las prácticas pastorales de la Arquidiócesis de Cali (1965-2019)”, este artículo se propone realizar un discernimiento teológico de los presupuestos eclesiológicos que animaron la acción pastoral de la Iglesia en la ciudad de Cali. Lo anterior se hizo a partir de la revisión del proceso histórico de la Arquidiócesis desde sus prácticas pastorales y planes pastorales elaborados entre 1965 y 2019, considerando con especial atención las concepciones de Pueblo de Dios, Iglesia

1 Doctorando en Teología en la Universidad Pontificia Bolivariana, Colombia. Director del programa de Especialización en Educación y Sagrada Escritura e investigador de Fundación Universitaria Católica Lumen gentium. Grupo de Investigación Yeshúa. Correo electrónico: jmayor@unicatolica.edu.co.

2 Doctorando en Teología en la Universidad Pontificia Bolivariana, Colombia. Magíster en Educación Universidad San Buenaventura de Cali. Teólogo de la Pontificia Universidad Javeriana, Bogotá. Docente e investigador de la Fundación Universitaria Católica Lumen gentium. Grupo de Investigación Yeshúa. Correo electrónico aolaya@unicatolica.edu.co. 
de comunión y participación y sinodalidad, que trajo en su momento el Concilio Vaticano II y los documentos de las conferencias generales del episcopado latinoamericano (Medellín, 1968; Puebla, 1979; Santo Domingo, 1992, y Aparecida, 2007). A partir de los presupuestos establecidos, se hizo una revisión de los documentos del archivo arquidiocesano y de algunos trabajos previos elaborados por otros investigadores, cuyo interés está en la sistematización de la presencia histórica de la Iglesia (Cali y el Valle del Cauca). El recorrido realizado permite identificar la forma en que esta Iglesia particular de Cali respondió tanto a las iniciativas de cambio propuestas en la Iglesia (universal y latinoamericana) como a los desafíos y retos que ha traído el devenir histórico de una ciudad en expansión. La disposición histórica para leer su quehacer pastoral en el horizonte teológico de los signos de los tiempos ha permitido configurar un estilo y una praxis pastoral que le ofrece grandes posibilidades para entrar en la dinámica sinodal.

Palabras clave: Eclesiología; Concilio Vaticano II, Pueblo de Dios; Medellín; Puebla; Aparecida; Arquidiócesis de Cali; Planes pastorales; Comunión y participación; Sinodalidad.

\section{Abstract}

On the occasion of the research project entitled The Sacred Scripture in the pastoral practices of the Archdiocese of Cali (1965-2019), this article proposes to carry out a theological discernment of the ecclesiological presuppositions that animated the pastoral action of the church in the city of Cali. This was done from the review of the historical process of the Archdiocese, from its pastoral practices and pastoral plans elaborated between the years 1965-2019, with a special attention on the conceptions of the People of God, Church of communion and participation and synodality, which were brought at the time by the Second Vatican Council and the documents of the General Conferences of the Latin American Episcopate (Medellín (1968), Puebla (1979), Santo Domingo (1992) and Aparecida (2007)). Based on the established assumptions, a review was made of the documents of the Archdiocesan archive and of some previous works prepared by other researchers whose interest is in the systematization of the historical presence of the Church (Cali and the Department of Valle del Cauca). The route carried out allows us to identify the way in which this particular Church of Cali responded both to the initiatives of change proposed in the Church (Universal and Latin American) and to the challenges that the historical evolution of an expanding city has brought. The historical readiness to read its pastoral work in the theological horizon of the signs of the times has allowed to configure a style and a pastoral practice that offers great possibilities to enter into the synodal dynamics.

Keywords: Ecclesiology; Vatican Council II; People of God; Medellín; Puebla; Aparecida; Archdiocese of Cali; Pastoral plans; Communion and Participation; Synodality. 


\section{Introducción}

Al revisar la historia de la Arquidiócesis de Cali (Colombia), es imposible desconocer el impacto de su labor evangelizadora en esta región y la adaptación a los retos que el desarrollo de la ciudad le imponía y que ella afrontó desde su respuesta evangelizadora. Sin perder la esencia del anuncio evangélico, por una parte, realizó unas actividades propias en el ámbito de lo sacramental, lo litúrgico y lo espiritual, al mismo tiempo que fue elaborando y prestando una ayuda a la ciudad desde una acción social que hace evidente la caridad y la misericordia, con el impulso de numerosas obras sociales; además de ser una innegable voz profética en las palabras, los discursos y las intervenciones de los jerarcas de la Arquidiócesis ante diversos momentos históricos difíciles que sufrió la ciudad en el contexto nacional, por los procesos del paramilitarismo, la guerra contra las guerrillas, el narcotráfico y la búsqueda de la paz para el país. Pero, detrás de esta presencia de la Arquidiócesis de Cali, cabe preguntarse cuáles son los presupuestos eclesiales y eclesiológicos que animaron la apuesta de la Iglesia en ciudad.

El propósito de este artículo es hacer una lectura interpretativa de la presencia histórica de la Arquidiócesis de Cali desde sus prácticas pastorales entre 1965 y 2019, que ayude a realizar un discernimiento teológico de los presupuestos eclesiológicos que animaron su presencia pastoral, desde las concepciones de la Iglesia como Pueblo de Dios, Iglesia de comunión y participación y la sinodalidad, en respuesta a los signos de los tiempos en el horizonte de la recepción latinoamericana del Concilio Vaticano II y los posteriores aportes de las conferencias episcopales latinoamericanas.

Se recurre a fuentes primarias como archivos y material documental de la Arquidiócesis de Cali y a otras publicaciones seriadas de la misma Arquidiócesis, desde las cuales se llega a evidenciar algunas de las líneas de la eclesiología brindada por el Concilio Vaticano II y su recepción novedosa en América Latina, y que en esta Iglesia particular se intentan asumir desde unas características propias en su quehacer eclesial. De aquí que se pretenda presentar algunas líneas de la eclesiología presente en las acciones pastorales de la Arquidiócesis de Cali. Tal pretensión se convierte en un aporte importante, pues los estudios que dan cuenta de este aspecto eclesiológico tienen muy poco estudio evidenciado en las búsquedas bibliográficas.

Las aproximaciones se encuentran en estudios de carácter histórico que sí representan una producción importante, especialmente en las obras de los profesores de la Universidad del Valle Antonio José Echeverry Pérez y Carolina Abadía Quintero con sus obras conjuntas Historia de la Iglesia católica en el Valle del Cauca (1927-1985) y Aproximación histórica a la Diócesis de Cali, quienes hacen un aporte importante a la historiografía de la Iglesia en el departamento del Valle y la ciudad de Cali. También un corto resumen de la presencia de la Iglesia de Cali en el siglo XX escrito por el teólogo Diego Agudelo Grajales, La Iglesia católica en Cali durante el siglo XX: Una presencia viva y desconcertante, en que expresa que es evidente "una presencia que es efectiva, pero desconcertante al mismo tiempo, edificadora y generadora de valores fundamentales y modelos de poder" (p. 124).

Dos publicaciones aporta la Arquidiócesis de Cali, con motivo de celebración de efemérides: Arquidiócesis de Cali, 1910-2010: Un alba iluminada. Recuento histórico y El descubrir pastoral. 50 años de la Arquidiócesis de Cali como sede metropolitana. También en la tesis para optar al título de magíster en Historia de Carlos Arturo Tolmos Méndez, en que el autor presenta un acercamiento a la comprensión de la forma concreta en que se hace la recepción del Concilio Vaticano II por el clero de la Arquidiócesis de Cali y los esfuerzos que se realizaron para su aplicación entre 1962 y 1979. Dos constataciones de su trabajo muestran el vacío que 
desde este artículo pretendemos ir llenando: "si bien los cambios producidos por el Concilio en la Iglesia local son muy grandes, aún existen algunos aspectos en los que falta una apropiación del Concilio, entre los cuales resalta el aspecto eclesiológico", y, segundo, agrega que "se ha podido constatar que no existe una memoria o documentación elaborada de todo este proceso" (Tolmos, 2018, p. 2).

Por lo anterior, se evidencian algunas líneas de la eclesiología presente en las acciones pastorales de la Arquidiócesis de Cali. Primero, se aborda la concepción de la Iglesia Pueblo de Dios propuesta en el Concilio Vaticano para acercarse a una primera lectura eclesiológica de la acción pastoral de la Arquidiócesis de Cali. Segundo, se analiza el planteamiento de una Iglesia de comunión y participación, asumido desde las realidades de América Latina, en los documentos de las reuniones generales del episcopado latinoamericano (Medellín, Puebla y siguientes), y cómo se van plasmando estos presupuestos eclesiológicos en los planes pastorales de la Arquidiócesis. Finalmente, se trata el concepto de sinodalidad, en continuidad con lo construido, para analizar los desafíos que estos elementos eclesiológicos traen para la concreción del plan pastoral 2019-2023 propuesto para la Iglesia particular de Cali.

En las conclusiones, se plantean los retos que restan para la Arquidiócesis, desde el punto de vista de consolidar un auténtico camino de sinodalidad, que abra a todos a un pensamiento de apertura renovadora, en que el discernimiento sea punto clave para sońar y llegar a una Iglesia sinodal, en que los laicos tomen consciencia plena de su lugar eclesial. Además, hacer que los laicos puedan asumir su ministerialidad sin que signifique entonces una clericalización de su labor de servicio a la Iglesia.

\section{Iglesia Pueblo de Dios}

Dado que "la eclesiología constituye el centro de perspectiva de la teología del Vaticano II" (Álvarez-Suárez, 2010, p. 325), es preciso comprender el significado del giro eclesiológico del Concilio y los retos que afrontó la Iglesia, para ello hacer una ubicación del tiempo precedente. Los primeros tratados de eclesiología datan de los siglos XIV y XV, en ellos se "presenta la Iglesia como sociedad puramente espiritual, desprendida totalmente de bienes materiales e incluso de ministerios al ser Cristo su única cabeza". De ahí que "la Iglesia se convierte en una realidad invisible, perceptible únicamente en la fe, formada por individualidades salvadas y predestinadas, sin vínculo recíproco entre ellas que las haga presentarse como sacramento en medio del mundo y de la historia" (Bueno, 1998, p. 8). De esta forma, los tratados de eclesiología creaban distancias insalvables entre todos los bautizados y acentuaban el poder de la jerarquía en la Iglesia.

Las definiciones a las que se llegó en la Baja Edad Media recogían lo que de plano ya se venía haciendo, y al mismo tiempo marcaría la pauta para otro periodo clave de la historia en la vida de la Iglesia: la modernidad. La respuesta de la Iglesia a las reformas del siglo XVI consolidaron expresiones eclesiales más de corte espiritual que situacional y más piramidal que comunitaria.

Por otra parte, la Iglesia católica antes del Concilio Vaticano II estuvo marcada por una fuerte tendencia legalista y enfatizaba su estructura jerárquica, centrada en la autoridad que de allí se derivaba. Esta centralidad en la autoridad jerárquica, especialmente del papa, no era gratuita, pues respondía a una forma de estar en el mundo, de responder a las situaciones que afrontaba y ante las cuales, ante todo, temía perder poder. El desarrollo y la conformación de los Estados liberales en la Europa del siglo XIX, 
no menos desafíos que ponían en tela de juicio la autoridad de la Iglesia en campos que el Estado ahora reclamaba para sí. Ejemplo de ello lo constituyó el reclamo de la supremacía del Estado secular y la defensa de la libertad de pensamiento, del liberalismo europeo, que influyó también en las nacientes repúblicas que emergían de las gestas independistas en América Latina, ${ }^{3}$ en que se propendió a reducir el poder temporal y la influencia de la Iglesia, por considerarla un obstáculo para la modernización económica, social y política de las naciones (De Roux, 2012, p. 9). Independizar y limitar el poder de la Iglesia frente al Estado implicó también un ataque a sus riquezas, privilegios y autoridad, reformas que requerían una destrucción del poder eclesiástico.

Todo lo anterior contribuyó a que la Iglesia católica, después de haber sido mayoritariamente regalista en el siglo XVIII, es decir, defensora de los privilegios de los reyes en asuntos eclesiásticos, terminara en la segunda mitad del siglo XIX siendo mayoritariamente ultramontana, o sea, defensora acérrima de la autoridad papal frente a los gobernantes civiles. (De Roux, 2012, p. 10)

El Concilio Vaticano II será el momento decisivo para replantear tales comprensiones, que conllevará de fondo la superación de los impactos de modelos eclesiológicos piramidales. Por tanto, parece no de poca importancia que la primera Constitución del Concilio Vaticano II tenga por objeto a la Iglesia, ${ }^{4}$ la cual se describe en razón de que es sacramento o signo del misterio salvífico de Cristo, quien es luz de las naciones. Esto quiere decir que la Iglesia es un signo visible de la presencia del Padre, del amor del Hijo y la fuerza del Espíritu, con énfasis en su presencia en el mundo no en respuesta reivindicativa de los privilegios arrebatados, sino con la consciencia de estar en esta historia para dar un anuncio evangélico a toda la humanidad y de las condiciones del mundo moderno en que se encuentra la Iglesia en tiempos que se reúne el Concilio Vaticano II, sentirse unida a todos los seres humanos por múltiples aspectos que atañen a todos, como es la ciencia, la tecnología y la cultura, desde donde se generan vínculos sociales, políticos y económicos (Pablo, 1964, n. ${ }^{\circ}$ 1). Esta manera de concebir la Iglesia adquiere una alta relevancia: salir del planteamiento societario, que colocaba a la Iglesia en paralelo con las sociedades civiles para insertarla en el entero evento salvífico, y dejar esa centralidad en torno a la jerarquía para reencontrarse como comunión de todos los bautizados, enriquecida con los dones, carismas y ministerios de cada uno de ellos, ante la misión que ha de cumplir en el mundo y en la historia. Y así toda la Iglesia aparece como "un pueblo reunido en virtud de la unidad del Padre y del Hijo y del Espíritu Santo" (Pablo, 1964, n.o 4). De esta manera, se reitera que esta Iglesia es dirigida por Dios, guiada y alimentada continuamente por el mismo Cristo, de esta manera quita el peso de la centralidad de la Iglesia en la jerarquía eclesiástica y forma ahora un cuerpo, cuya cabeza es Cristo.

3 Ante este enemigo detectado y definido como liberal, masón, protestante y positivista, la Iglesia católica tuvo una respuesta más centralista (romana), agresiva y que sobrevaloró la jerarquía eclesiástica: "Con el apoyo decidido de la Santa Sede, la Iglesia latinoamericana se renovó sobre todo a partir del último tercio del siglo XIX gracias a ese proceso de restauración que se propuso modelar al clero, a las estructuras eclesiásticas y a la sociedad según los designios 'romanos', con todo lo que aquello implicaba de rigor doctrinal y jerárquico" (De Roux, 2014, p. 36).

4 El paso de la eclesiología del Concilio Vaticano I a la del Concilio Vaticano II tiene un amplio recorrido, que no es cometido describir minuciosamente, pero está desarrollado en diversos textos que, por una parte, describen recorridos históricos de la Iglesia, como lo hacen los referenciados de Rodolfo de Roux; otra literatura nos cuenta el proceso que se vivió durante las sesiones preparatorias y el desarrollo del mismo Concilio Vaticano II, y, finalmente, los otros textos de la recepción del Concilio después de su promulgación. Entre los más destacados: Giuseppe (2015), Giuseppe y Jossua (1987), Alberti (2013), Madrigal (2005, 2015) y Azcuy (2013). 
Las imágenes utilizadas en la constitución Lumen gentium para designar a la Iglesia (Pablo, 1964, n. ${ }^{\circ}$ 6) marcan, sin duda, una diferencia respecto de la eclesiología precedente: redil (Jn 10, 1-10); grey que es guiada por Dios como Pastor (Is 40, 11; Ez 34, 11-16); labranza, edificación Dios (1 Cor 3, 9); piedra angular sobre la que se edificará la Iglesia (Mt 21, 42; 1 Cor 3,11); casa/tienda de Dios, madre nuestra $(\mathrm{Ga} 4,26)$; esposa del Cordero "amó y se entregó por ella para santificarla" (Ef 5,25-26); figuras todas ellas tomadas de textos del Antiguo y Nuevo Testamento, acentuando de esta manera una obligada mirada y escucha atenta de la Palabra, pues como se expresa en la constitución Dogmática Dei Verbum ella es considerada como "la regla suprema de su fe, puesto que, inspiradas por Dios y escritas de una vez para siempre, comunican inmutablemente la palabra del mismo Dios, y hacen resonar la voz del Espíritu Santo en las palabras de los Profetas y de los Apóstoles" (n. 21).

El capítulo II de la Lumen gentium, se va a "concentrar en presentar a la Iglesia como Pueblo de Dios" (Parra, 1979, p. 51), que implica los siguientes aspectos: Pueblo de Dios, en continuidad con el pueblo de Israel del Antiguo Testamento, siendo pueblo elegido, sacerdotal y consagrado a Dios, en el cual se siguen cumpliendo las promesas de una historia de salvación. Pueblo que hoy sigue siendo llamado a ser testimonio de la fe recibida y que en actitud profética actualiza la misión guiado por el Espíritu, y construye la vida de la comunidad desde los diversos carismas que en ella se suscitan. Acción que repercute en el bien de toda la humanidad, que, viviendo en unidad, se abre a la universalidad de todas las naciones y de las todas personas, sean ellas de otras religiones o ateas. Por tanto, un pueblo que tiene, como exigencia esencial, la misión y, en la base, la comunión (Pablo, 1964, n. 9-17).

Además, el Concilio Vaticano II permitió redescubrir el sentido y vital importancia de la Iglesia local (Polanco, 2020, pp. 31-68), continental, nacional, diocesana y de comunidades, así como que por todas partes se dé una emergencia de eclesiologías locales que responden a los contextos más cercanos en que desarrolla su actividad pastoral y misionera. De allí se explica el camino que ha hecho la Iglesia latinoamericana, animada desde las conferencias generales realizadas en Medellín (1968), Puebla (1979), Santo Domingo (1992) y Aparecida (2007), sin olvidar el antecedente del encuentro en Río de Janeiro (1955); 5 camino que ha realizado una recepción del Concilio de manera profética, evangélica y decidida en favor de los pobres. Como lo expresa Codina (2008b):

La aplicación del Concilio Vaticano II, sobre todo a partir de la metodología de Gaudium et spes, mucho más que una mera trasmisión de una doctrina: ha sido una relectura creativa desde un contexto latinoamericano marcado por la pobreza, la injusticia y por diferentes culturas. Estamos ante una verdadera eclesiología latinoamericana y del Caribe. (p. 133)

Esta visión de la Iglesia, esencialmente misionera, encuentra en Gaudium et spes, el otro viraje eclesiológico hacia una Iglesia que se abre a los signos de los tiempos del mundo contemporáneo:

Los gozos y las esperanzas, las tristezas y las angustias de los hombres de nuestro tiempo, sobre todo de los pobres y de cuantos sufren, son a la vez gozos y esperanzas, tristezas y angustias de los discípulos de Cristo.

5 En dicha conferencia se fundó el Consejo Episcopal Latinoamericano (Celam), primero del mundo en su género. 
Nada hay verdaderamente humano que no encuentre eco en su corazón. [...] La Iglesia por ello se siente íntima y realmente solidaria del género humano y de su historia. (Pablo, 1965, n. ${ }^{\circ}$ 1)

En América Latina, estas palabras fueron parte de un faro que guio la voluntad de pensar y discernir las mociones del Concilio Vaticano II, así como hacer una aplicación a la realidad de los pueblos empobrecidos, siguiendo las orientaciones de Gaudium et spes: "Esto llevó a un proceso reflexivo creativo que implicó afrontar la aparición de lo político en la teología y exigió el paso desde una teología del desarrollo, deudora de Lebret, a una nueva orientación teológica, latinoamericana y de la liberación, cuyo principal pionero fue Gutiérrez" (Azcuy, 2013, p. 140).

Estas ideas emanadas del Concilio Vaticano II fueron calando en la forma en que en América Latina se fue gestando una eclesiología que tendrá en la comunión y la participación unos pilares fundamentales de una nueva forma de ser Iglesia.

\section{La eclesiología de comunión y participación en los planes de pastoral de la Arquidiócesis de Cali}

En las reuniones generales del episcopado latinoamericano de Medellín (1968) y Puebla (1979), tuvo una relevancia fundamental la concepción de una Iglesia de comunión y participación, que verá en los planes pastorales una forma de hacer viable tal concepción eclesial.

\section{¿Qué son los planes pastorales?}

Es importante dar un repaso a la historia para entender de dónde surgen y qué son los planes pastorales. Seguimos a Vela (2002), quien inicia exponiendo que los planes pastorales son una aplicación del concepto de planificación social al concepto de pastoral de conjunto, que van a tener una estructura básica parecida: "análisis de la realidad y diagnóstico de prioridades, determinación de fines y objetivos, y toma de decisiones sobre los medios e instrumentos a aplicar" (p. 178). Los planes sociales, entendidos como procesos encaminados a un cambio social, tuvieron en América Latina un interés marcado a partir de los estudios e informes sobre la realidad económica elaborados por la Comisión Económica para América Latina y el Caribe (Cepal, s. f.), desde los cuales se analizan los factores que impiden el desarrollo de la región y cómo la planificación sería un instrumento eficaz para el desarrollo social.

Esta visión de los planes sociales está en el trasfondo teórico de los planes pastorales, que van a permitir la adaptación de la "llamada pastoral de conjunto, como la acción coordinada de toda la Iglesia como Cuerpo de Cristo [...] o, como lo afirma también el Vaticano II, como Pueblo de Dios" (Vela, 2002, p. 183), haciendo que la tarea evangelizadora tenga una planificación. El Concilio Vaticano marca esta fundamentación al proponer la corresponsabilidad de todos sus miembros en la construcción de la Iglesia.

En la Conferencia de Medellín (1968), se apuntan elementos clave para esta planificación: estudio de la realidad en colaboración con organismos especializados en estos temas sociales, hacer una reflexión 
teológica sobre esa realidad analizada, disponer del material humano para responder a las exigencias de la realidad, determinar prioridades de acción, elaborar el plan pastoral en atención a los pasos de la planificación y evaluar periódicamente estas planeaciones (Vela, 2002, pp. 184-186).

Posteriormente, en la Conferencia de Puebla (1979), además de la insistencia del diagnóstico de la realidad latinoamericana, como parte de la acción evangelizadora, va a exponer los diversos términos de la estructura de la planificación: objetivo general, criterios, objetivos específicos, metas y líneas (Vela, 2002, pp. 186-193). Finalmente, esta planeación tendrá en los agentes de pastoral un punto neurálgico para llevarse a cabo, pues como lo propone Vela (2002), "el agente de pastoral se incultura con su grupo cristiano, ejerciendo una doble función de atestación (confirmación de ese mismo orden cultural y social) y de contestación de todo lo que sea pecado e injusticia. Solo así podrá evangelizar el Reino” (p. 200).

\section{Las conferencias de Medellín y Puebla: perspectivas para la planeación pastoral}

Antes del Concilio Vaticano II, en América Latina la teología que se producía era una forma de repetir los temas teológicos desarrollados en Europa, desde lo cual se puede decir que no hay propiamente una teología latinoamericana. Escribía Joseph Comblin, citado en Costadoat (2020), que "sin historia la teología será en Latinoamérica una pura imitación o una repetición servil de temas europeos” (p. 442).

Pero la Conferencia de Medellín "marcará un antes y un después. La recepción latinoamericana del Concilio impulsó grandes cambios en la teología [...] después de esta Conferencia, la producción teológica latinoamericana es impresionante" (Costadoat, 2020, p. 442), que implicó una profunda transformación de la Iglesia latinoamericana y de la forma de leer, interpretar y relacionarse con la sociedad: "No basta, por cierto, reflexionar, lograr mayor clarividencia y hablar; es menester obrar. No ha dejado de ser esta la hora de la palabra, pero se ha tornado, con dramática urgencia, la hora de la acción" (Celam, 1968, Introducción a las conclusiones, n. ${ }^{\circ}$ ), convirtiéndola en voz profética defensora de los pobres, de los que sufren. La recepción del Concilio Vaticano II, desde Medellín, había puesto las bases para superar la ambigüedad política que había caracterizado a la Iglesia y la preocupación por una práctica sacramental sin compromiso, que lentamente fueron superadas y la insertaron en la realidad sufriente de la sociedad continental. Por tanto, se asume la Iglesia como sacramento y liberación, dada las difíciles situaciones de orden económico, político y social que vivía el continente en ese momento:

No podemos dejar de interpretar este gigantesco esfuerzo por una rápida transformación y desarrollo como un evidente signo del Espíritu que conduce la historia de los hombres y de los pueblos hacia su vocación [...]. No podemos, en efecto, los cristianos, dejar de presentir la presencia de Dios, que quiere salvar al hombre entero, alma y cuerpo. (Celam, 1968, Introducción a las conclusiones, n. ${ }^{\circ}$ 4)

De esto, se evidencia que "la centralidad de la 'Iglesia pobre y para los pobres' constituye una actitud eclesiológica que responde al llamado del Vaticano II de ser una Iglesia cristocéntrica” (Iberico, 2018, p. 46). Unido a esto, encontramos un elemento clave, inédito casi en la formulación y producción teológica hasta ese momento, que lo constituye el método ver-juzgar-actuar. De hecho, tanto en la marcha misma de la Conferencia de Medellín como en la posterior apuesta eclesiológica, puede sostenerse: 
La comunidad eclesial, sin preocuparse por sospechas alarmistas, se valió del método para poner en práctica su fe y precisar su misión como también su reflexión teológica. [...] Los obispos "pastoralistas" intuyeron que en la cuestión del método estaba en juego no solamente un esquema operativo, sino la manera peculiar de profesar su fe (discipulado) y realizar su misión en la comunidad eclesial. (Schickendantz, 2012, p. 44)

Este método significa, como otro gran aporte de Medellín a la eclesiología, asegurar que los resultados de los documentos no se queden solo plasmados en escritos, sino que ellos impacten en la realidad los problemas que aquejan a la humanidad.

Se diría que este modelo busca proclamar de manera gozosa el mensaje de Cristo, Señor de la historia, vencedor del pecado y de la muerte. Desde la dimensión eclesial de la diakonía, la Iglesia se pone en actitud de escucha de la Palabra, la vive, la transmite, la celebra y la hace suya, pero además la asocia en una dinámica que se traduce en presencia viva y operante en una comunidad conformada por pobres y marginados, que aceptan el mensaje, adaptado a las realidades, conservado en su integridad y convertido en alimento y sostén en las desventuras del día a día, formando así la nueva familia de Jesús, al escuchar la Palabra y llevarla a la praxis. (Mendoza, 2020, p. 63)

La Conferencia de Medellín significó el reto eclesial de ser capaz de reconocer la centralidad de los problemas y desafíos sociales, culturales, políticos y económicos del continente, como estímulos para la reflexión teológica y forjar una espiritualidad de compromiso con los pobres y las realidades que aquejan a la gran mayoría de latinoamericanos, alejándolos de la posibilidad de una vida digna.

Luego, en la Conferencia de Puebla (1979), se hizo eco del Concilio Vaticano II en proponer una eclesiología caracterizada por la comunión y la participación. Eclesiología que retoma los elementos más fundamentales y perennes de la Iglesia para hacer la adaptación a cada tiempo. Como propone Parra (1979):

Las líneas para una eclesiología de comunión que dinamicen cuanto de positivo existe en nuestras comunidades y que contrarreste los pavorosos anti-signos de comunión en los niveles social, cultural y eclesial, no quieren ser o, por lo menos, no deben ser unos "principios doctrinales" sino fundamentalmente un programa de acción y de transformación. (p. 130)

El documento de Puebla continúa con la perspectiva que la anterior conferencia episcopal había trazado, en la cual la realidad de injusticia, desigualdad y marginación implica la vida misma de la Iglesia, no solo por la interpelación de la realidad a la acción evangelizadora, sino también por los cambios que trae consigo para su vida y estructuración interna, en clave de liberación y construcción del Reino.

El objeto primario de esta enseñanza social es la dignidad personal del hombre, imagen de Dios y la tutela de sus derechos inalienables [...]. [...] Por tanto, la finalidad de esta doctrina de la Iglesia -que aporta su visión propia del hombre y de la humanidad [...]- es siempre la promoción de liberación integral de la persona humana, en su dimensión terrena y trascendente, contribuyendo así a la construcción del Reino último y definitivo, sin confundir, sin embargo, progreso terrestre y crecimiento del Reino de Cristo. (Celam, 1979, n.o 475) 
Las líneas pastorales propuestas en el documento (Celam, 1979, n. ${ }^{\circ}$ 1153-1165) destacan que el objetivo de la opción por los pobres es el anuncio de Cristo Salvador, en un proceso de liberación de todas aquellas situaciones que no permiten la realización plena de la dignidad de las personas, opción exigida por la escandalosa situación de pobreza de millones de habitantes del continente, que conlleva una exigencia, por un lado, de la trasformación de las condiciones sociales, políticas y económicas que generan tal situación de extrema pobreza, y por otro, la exigencia evangélica de la pobreza como signo de solidaridad efectiva con quienes sufren. Exigencia que para hacerse real invita a la Iglesia a "revisar sus estructuras y la vida de sus miembros, sobre todo de los agentes de pastoral, con miras a una conversión efectiva" (Celam, 1979, n. ${ }^{\circ}$ 1157), en una vida austera y de total confianza en Dios, y de esta manera "presentará una imagen auténticamente pobre, abierta a Dios y al hermano, siempre disponible, donde los pobres tienen capacidad real de participación y son reconocidos en su valor" (n. $\left.{ }^{\circ} 1158\right)$.

\section{El inicio de los planes de pastoral en la Arquidiócesis de Cali}

La Iglesia local de Cali es constituida en Arquidiócesis en 1964, en el contexto de la realización del Concilio Vaticano II, y caracterizada por unas condiciones sociales, políticas y económicas de fuerte crecimiento, pero generadora de nuevas dificultades:

El florecimiento económico de la ciudad, de la mano de una mayor influencia social, política, cultural y espiritual en la región, son el marco que justifica la conversión de la Diócesis de Cali en Metropolitana el 20 de junio de 1964. Monseñor Alberto Uribe Urdaneta (1960-1985) fue el quinto Obispo de la Diócesis y primer Arzobispo de Cali. (Arquidiócesis de Cali, 2014, p. 47)

El periodo conciliar y posconciliar más cercano tuvo en la figura de monseñor Alberto Uribe Urdaneta la persona que dirigió la apuesta pastoral de la ciudad, en un periodo bastante largo, entre 1964 y 1985. En este, todavía no se puede hablar de planes pastorales propiamente, sino de una pastoral encaminada a crear centros parroquiales, los cuales tenían una estructura que respondía no solo al aspecto religioso, sino también a una comprensión más amplia de la formación de la persona.

Para entender el porqué de la construcción de los centros parroquiales y aquello que ofrecían, es importante describir unos aspectos importantes que se leen en un informe que monseñor Urdaneta (1964) envió al nuncio apostólico en Colombia, José Paupini, con motivo de un informe solicitado por el nuncio sobre la situación del Valle del Cauca y en especial de la diócesis de Cali. El primer aspecto referenciado es la educación: según el informe, casi la cuarta parte de la población del departamento es analfabeta y un déficit de 1500 aulas para 57710 nińos en edad escolar. Ante esta realidad, se hace énfasis en la urgencia y necesidad que debe hacerse en materia educativa para la diócesis de Cali (en ese momento todavía no era arquidiócesis).

Otro apartado del informe es el relacionado con la situación social. La principal preocupación es el vertigionoso crecimiento poblacional, debido a diversas migraciones que se dan en esos años en todo el país y que tienen en el Valle del Cauca un territorio de recepción de estos migrantes internos, "formando un conglomerado en todo sentido heterogéneo sin tradiciones ni mutuo conocimiento" (Informe al nuncio 
apsotólico, 1964, p. 6). Expone que en Cali, en los últimos diez ańos, la población pasó de 150000 a 750770 habitantes, aumento este que agrava la situación educativa mencionada (1560 aulas de déficit), además de un déficit en la vivienda ( 55000 , según el informe) y, por supuesto, un desempleo que es estimado en un $46 \%$.

El informe termina con una mirada al desarrollo industrial que trae consigo la industria azucarera, y brinda un porvenir para el departamento. Para ese momento, existían 20 ingenios con 30000 obreros, de los cuales dependían económicamente 120000 personas. Mirada optimista que contrasta con el problema, común a todo el país, de la violencia desencadenada entre los liberales y los conservadores. ${ }^{6} \mathrm{En}$ las conclusiones, se resalta la relación de la situación del país y la manera en que hace presencia la Iglesia, siendo esta una fuente de alivio e influencia en la sociedad:

Las posibilidades económicas del Departamento del Valle y por tanto la afluencia de gentes que en forma sorpresiva lo han invadido, han suscitado en los diez últimos ańos un problema de carácter espiritual y material de grandes proporciones. La Iglesia católica sin embargo, viene conservando una influencia definitiva en todos los sectores sociales. (Informe al nuncio apostólico, 1964, p. 11)

Desde este informe, es posible relacionar la intención de los centros parroquiales, construidos en los lugares de nuevos asentamientos poblacionales que fueron apareciendo en los límites de la ciudad y con poblaciones con grandes dificultades económicas, en los cuales se atendería el aspecto religioso y espacios de formación religiosa (el templo salón parroquial), y otros aspectos vitales que en ese momento parecía urgente atender como la educación (escuela parroquial, normales superiores o jardines infantiles), la recreación (campos deportivos, teatros al aire libre o juegos infantiles), la salud (dispensarios) y, en algunos centros parroquiales, la alimentación con comisariatos (que ofrecían productos con precios asequible a las comunidades obreras y trabajadoras).

Más adelante, en 1976, la Arquidiócesis cuenta con un departamento de diseño propio, el cual hace un estudio de cada una de las nuevas construcciones que va a emprender, ahora con un cambio en la denominación de centros parroquiales a centros católicos de evangelización. El estudio de estas se realiza con datos de la población estimada, con el promedio de salario de los trabajadores habitantes de la zona, la cercanía a la parroquia más cercana y las deficiencias en salubridad, educación y zonas verdes. ${ }^{7}$ Eso sí, la Arquidiócesis solo se va a encargar de la construcción de la parte parroquial, pero se une a las iniciativas de un programa de dotación de servicios comunitarios iniciado por la Administración municipal, con los entes encargados de estos temas sociales (vivienda, educación, recreación): escuela primaria, guardería infantil, centro de salud, salón múltiple y culturización, canchas deportivas, parque (jardines), juegos infantiles y puesto de policía, que tienen como objetivo una "política de integración de las áreas marginales, a partir de la dotación de servicios comunitarios, encaminada a la protección de la familia con la prestación de servicios de preescolares y escolares, en una acción directa del estado en los campos de salud, cultura, nutrición y recreación" (Arquidiócesis de Cali, 1976, p. 2).

6 Situación acentuada con el asesinato de Jorge Eliécer Gaitán y el Bogotazo en 1948.

7 Archivos de la curia de la Arquidiócesis de Cali. Departamento de Diseño de la Arquidiócesis de Cali. Posible construcción de centros católicos de evangelización (diciembre de 1976). 
El periodo como arzobispo de la ciudad de monseñor Alberto Uribe Urdaneta deja para la ciudad la construcción de 23 centros parroquiales en las décadas de 1960 y 1970, 24 centros católicos de evangelización en las décadas de 1970 y 1980, y 17 parroquias en el periodo de 1980-1985. De este extenso lapso, se pude asegurar que la presencia eclesial tiene un alto sentido e injerencia en la vida social de Cali, sin que se pueda especificar con claridad una línea eclesiológica, pero que sí hará tránsito del discernimiento a la elaboración de planes pastorales, en los cuales sí se va lograr plasmar unas líneas eclesiológicas, como "un asunto de comunión y de trabajo cotidiano que permitirá potenciar la relación entre Dios y la humanidad específica de este territorio Arquidiocesano para construir una singularidad espiritual y social” (Arquidiócesis de Cali, 2014, p. 144).

Inicia el periodo de monseñor Pedro Rubiano, en 1985, quien presenta el plan pastoral con el siguiente objetivo general: "Construir una Iglesia arquidiocesana, en comunión y participación, como Pueblo de Dios, viviendo el compromiso radical del Evangelio, para anunciar al mundo de hoy el Reino de Dios" (Arquidiócesis de Cali, 1985, p. 10).

En este objetivo, es importante resaltar la idea de una Iglesia particular (no la abstracción de una iglesia universal), que encuentra en las realidades propias de una región un punto cierto de anclaje para desarrollar su cometido evangelizador. Después aparecen dos aspectos eclesiológicos derivados de esa reflexión que las conferencias de Medellín y Puebla han generado en las enunciaciones y las prácticas en América Latina: comunión y participación.

El caminar del Pueblo de Dios, en la diócesis de Cali (1910), y desde 1964 como arquidiócesis, pretende, con este plan pastoral de los setenta y cinco años de Iglesia particular, cumplir la misión encomendada por Cristo de anunciar a todos los hombres el Reino de Dios, en el convulsionado momento histórico que vive el país (década de 1980). ${ }^{8}$ En la presentación del plan pastoral, se entrevé el carácter de continuidad, que valora lo realizado, recoge la experiencia del pasado y mira los problemas actuales, en una respuesta eficaz: "No podemos seguir improvisando la Acción pastoral, dejándola a la buena voluntad de unos cuantos, es necesario contar con estructuras orgánicas que canalicen todos los esfuerzos humanos, para lograr una renovación espiritual en este momento histórico que nos toca vivir" (Arquidiócesis de Cali, 1985, p. 10). En esta intencionalidad, urge la necesidad de formar agentes de pastoral que sean capaces de vivir y trasmitir el mensaje evangélico en cada sector, en una clara apertura a posibilitar la capacitación y el desarrollo de la ministerialidad laical y no centrado en la parroquia, sino en la conformación de pequeñas comunidades (más adelante, se hará un esfuerzo por la conformación de comunidades eclesiales de base [CEB], que, al parecer, no fue muy exitoso en toda la ciudad), basados en tres pastorales: social, familiar y educativa, en las cuales se planteen metas y objetivos precisos de acuerdo con las múltiples necesidades que se presenten en cada campo.

Para este periodo, se divide la Arquidiócesis en tres zonas pastorales: la zona 1, la parte central y norte de la ciudad, los municipios de Yumbo y Dagua y sector rural; la zona 2, el sur de la ciudad, una parte

8 En la reunión de la XLIV Asamblea de la Conferencia Episcopal de Colombia de 1985, el mensaje de pastoral emitido fue un pornunciamiento frente a la situación actual del país, especialmente centrado en + la paz. El segundo apartado del documento, procura presentar la respuesta cristiana ante la situación descrita, para que a "la luz de la fe cristiana, descubrir en esta realidad el signo de un llamamiento de Dios” (Conferencia Episcopal de Colombia, 1985, n. ${ }^{2}$ 21, p. 9). 
rural y la población de Jamundí, y la zona 3, la parte oriental de la ciudad. Antes de la elaboración del plan pastoral 1990-1992, se realizó una evaluación ${ }^{9}$ de dos aspectos: el plan de opción por los pobres y cómo se ha visto la división por zonas.

$\mathrm{Al}$ evaluar el primer aspecto, se tienen unas respuestas que dejan entrever una realidad eclesial diversa, pero que refleja al mismo tiempo la calidad del compromiso frente a la opción por los pobres, según los sectores: en las zonas 1 y 2, que en la ciudad corresponden (en 1989, ahora ha cambiado en algunos aspectos) al centro (en su mayoría zona comercial) y al norte (residencial de estratos medios y altos), y al sur (residencial de estratos medio y alto, en pleno auge urbanístico), respectivamente; en estas dos zonas, en las respuestas recogidas, está que "no se ha asimilado", "faltó motivación por parte del clero de la zona", "quedó más como un lema que como un plan", "fue un error mezclar sacerdotes y laicos en el curso de opción por los pobres" (Arquidiócesis de Cali, 1989, p. 2), en contraste con la zona 3, que tiene a las comunas del oriente de la ciudad (los asentamientos donde mayoritariamente llegaron los desplazados a Cali, zona de obreros, de estratos bajos), las respuestas expresan que, aunque se anota que el curso de opción por los pobres no dio los frutos que se esperaban, parece que moviliza a "ser un llamado y un proceso, respondiendo según la realidad de cada sector", "llevando a sacerdotes y religiosos a estudiar el tema y estudio de la realidad", "el plan despierta al compromiso de reflexión-acción", "existe una participación en varios niveles" (Arquidiócesis de Cali, 1989, p. 3).

La evaluación de la división por zonas pastorales permite ver los adelantos que el clero de Cali ve desde el punto de vista de la organización y de un mejor acompańamiento pastoral del arzobispo y sus obispos auxiliares a las zonas y el encuentro más humano y fraterno con la comunidad. Al mismo tiempo que reconocen las necesidades de mayor formación tanto del clero mismo como de otros agentes de pastoral (religiosos y laicos) para cumplir la misión evangelizadora en temas de análisis de la realidad y de actualización bíblica. Lo anterior con miras a una mayor pastoral de conjunto, en que los agentes de pastoral intervienen de manera activa en la consolidación de una Iglesia en comunión y participación de todos los miembros que la integran. En esta dinámica de evaluación por zonas pastorales en la Arquidiócesis de Cali, nace el plan pastoral 1990-1992, el cual va a presentar como objetivo general "construir la Iglesia Arquidiocesana en comunión y participación, como Pueblo de Dios, viviendo el compromiso radical del Evangelio, dentro del Espíritu de la Nueva Evangelización, para anunciar al mundo el Reino de Dios”.

Para alcanzar este objetivo, se proponen unas políticas y estrategias que pueden resumirse en estudiar la realidad particular, formar agentes de pastoral, potenciar al laicado, apoyar a las instituciones de servicio existentes en el sector, dinamizar el servicio de las pastorales especializadas, formar en cada parroquia el consejo parroquial y el consejo de administración y favorecer el estudio y la formación de CBE. En 1995, termina el periodo de monseñor Rubiano.

9 El documento de Puebla propone que "laas formas concretas y los procesos pastorales deberán evaluarse según esos criterios característicos del Evangelio vivido en la Iglesia, todo debe hacer a los bautizados más hijos en el Hijo, más hermanos en la Iglesia, más responsablemente misioneros para extender el reino. En esa dirección ha de madurar la religión del pueblo" (Celam, 1979, n. $\left.{ }^{\circ} 259\right)$. 
Después del periodo de monseñor Rubiano, inicia el periodo de monseñor Isaías Duarte Cancino (1995-2002). Este tiempo será recordado por la presencia de un obispo que fue asesinado, el 16 de marzo de 2002, por su postura frente a las guerrillas, el narcotráfico y el paramilitarismo.

Monseñor Isaías Duarte en este tiempo de conflictos habló y denunció sin vacilaciones sobre los riesgos de la narcopolítica, la corrupción, la perpetuación de la guerra y la penetración del narcotráfico en la vida de comunidad. Profetizó sobre la necesidad de buscar caminos cristianos a esta crisis de valores enquistada en la sociedad. (Arquidiócesis de Cali, 2014, p. 51)

La presencia eclesial de la Arquidiócesis en la ciudad estará indudablemente marcada y centrada en la figura de monseñor Isaías Duarte ${ }^{10}$ sin que esto signifique un retroceso en el avance de unas acciones pastorales. En este periodo, es importante resaltar la continuación, en algunos casos, y la creación de muchas obras sociales en la Arquidiócesis, que continúan vigentes, cristalizadas en varias fundaciones de orden social, educativo y de formación: la creación de la Fundación Universitaria Católica Lumen Gentium (Unicatólica) (1996), el Centro de Investigaciones de la Arquidiócesis de Cali (1997), la Federación Católica de Educación (Conaced) (1998), la Fundación para la Educación de la Juventud de Escasos Recursos Económicos (2000), la Comisión Arquidiocesana Vida Justicia y Paz (1996), Samaritanos de la Calle (1998), el Centro Arquidiocesano del Migrante (1999), el Banco de Alimentos (2000), la Fundación SerGente (2000), la Fundación Pro-Vida Digna (2001), el Centro de Espiritualidad San José (1998), el Seminario Mayor Arquidiocesano San Vicente de Paul (1998) y la Acción Católica Arquidiocesana (1999).

Estas fundaciones reflejan las acciones y el carácter pastoral de la Arquidiócesis durante este periodo, movilizadas tanto por la preocupación de dar una respuesta eficaz a las situaciones sociales, políticas y económicas de la región como por el carácter evangélico que lo impulsaba.

El pensamiento sobre la Iglesia era la proyección de Monseñor para todas las realidades de la Arquidiócesis de Cali, como iglesia particular que debía responder a un mundo desafiante, globalizado y engreído, absortos por las luces de la infamia y alejado de Dios. [...] Pensó que la pastoral tenía que estar basado en los agentes de pastoral, las familias y las comunidades, pensaba en una iglesia que se ocupara de las personas en un contexto familia. [...] Para hacerlas capaces de hacer comunidad, de integrarse a la sociedad como ser libre y responsable. (Montoya, 2012, p. 55)

Después del asesinato de monseñor Isaías Duarte, viene el periodo de monseñor Juan Francisco Sarasti, quien, además de asumir un compromiso con la educación de la juventud de la ciudad y potenciar los proyectos alimentarios para los más necesitados, fue el arzobispo que organizó y lideró el sínodo arquidiocesano con ocasión de los cien años de la Arquidiócesis. Los logros del sínodo están condensados en dos documentos que recogen los elementos centrales que han de caracterizar la ruta del plan pastoral 2010-2020 (Arquidiócesis de Cali, 2011a), expresados en misión, visión, pilares, temas, objetivos y planes de acción. Como síntesis de esos documentos, se ve reflejado el espíritu del documento de Aparecida (misión) y el deseo de ser una Iglesia en comunión, misionera, en conversión constante y que camina del lado de

10 Un buen acercamiento a la vida de monseñor Isaías Duarte en Montoya (2012). Se recogen diversos testimonios de las personas que estuvieron a su lado, con lo que se logra un recorrido histórico por su vida y obras, y una semblanza tanto del pastor como del ser humano que fue. 
los pobres y excluidos (visión) (Arquidiócesis de Cali, 2011b, p. 49). Tras la renuncia a la silla arzobispal, vendrá monseñor Darío de Jesús Monsalve, quien asumirá el reto trazado por el sínodo arquidiocesano de 2010. La continuación de este ambicioso plan pastoral sinodal se materializará en 2019 cuando se presente a la Iglesia particular de la ciudad la apuesta por ser una Iglesia sinodal.

\section{Hacia una Iglesia sinodal en la Arquidiócesis de los retos del plan pastoral 2019-2023}

Antes de entrar a presentar lo que denominamos la apuesta hacia una Iglesia sinodal en la Arquidiócesis, es preciso remitirse, primero, a la fuente de este proyecto renovador de la Iglesia. El Concilio Vaticano II es la apuesta de renovación más grande de esta en cuanto a su ser y hacer que se haya llevado a cabo en los últimos cinco siglos. La necesidad de renovación tuvo como base dos grandes presupuestos. En primer lugar, la forma en que la Iglesia debía ejercer y entender su lugar en la historia y en la sociedad, lo que implicaba un siguiente paso: revisar su naturaleza. El gran hito de renovación lo plasmó el Concilio en la constitución Lumen gentium, en que se fijó el giro de una eclesiología jerárquica y piramidal a una Iglesia pueblo de Dios de Dios y sinodal. ${ }^{11}$ Con este giro, la Iglesia del Vaticano II no pretendía solo adaptarse a los tiempos que vivía, más bien era la posibilidad de volver a las raíces, al Evangelio mismo. Si bien "el Concilio será conocido como el Concilio Eclesiológico", es significativo que "la Eclesiología de este periodo será distinguida como la Eclesiología de la Comunión y de la Participación” (Parra, 1979, p. 117), lo que nos pone de nuevo en la ruta del camino a la sinodalidad.

De ahí que el doble desafío del Concilio Vaticano II es sacar a la Iglesia de su "eclesiocentrismo y jerarcología" (Bueno, 1998, p. 5). De esto, la gran importancia que significa que la primera constitución del Concilio tenga por objeto a la Iglesia, y la describa como luz para las gentes, en razón de que es sacramento y signo del misterio salvífico de Cristo. Ahora bien, ¿qué giros debía dar la Iglesia para lograr este propósito? Bueno (1998) expone dos:

a. Salir del planteamiento societario, que coloca a la Iglesia en paralelo con las sociedades civiles, para insertarla en el entero evento salvífico y b. dejar de girar en torno a la jerarquía para reencontrarse como comunión de todos los bautizados, enriquecida con los dones, carismas y ministerios de cada uno de ellos; todos ellos proceden de la dimensión mistérica de la Iglesia de cara a la misión que ha de cumplir en el mundo y en la historia. (p. 5)

En palabras más actuales, los desafíos que presenta Bueno (1998) describen la ruta inicial que la Iglesia ha de transitar para llegar a la sinodalidad, lo que implica pasar por la conversión pastoral.

Con el Concilio Vaticano II, no solo hay una nueva eclesiología, en realidad también hay una nueva ruta pastoral que busca poner a la Iglesia en el contexto de lo que está ocurriendo a su alrededor, para lo cual es necesario salir de sí misma e ir al encuentro del otro. Y para lograr este propósito la Iglesia necesitaba

11 Si bien como expone la Comisión Teológica Internacional (2018(, “el término y el concepto de sinodalidad no se encuentren explícitamente en la enseñanza del Concilio Vaticano II, se puede afirmar que la instancia de la sinodalidad se encuentra en el corazón de la obra de renovación promovida por él” (n. ${ }^{\circ}$ 6). 
salir de la concepción de dominio y superioridad que la había caracterizado desde los tiempos de la Edad Media. Al concebir a la Iglesia como luz de las gentes, como Pueblo de Dios, la eclesiología del Vaticano II quiso ponerla en contexto (salir de sí misma), para ir al encuentro del hombre, o como lo ha llamado el papa Francisco $\left(2013\right.$, n. $\left.^{\circ} 20\right)$, una Iglesia en salida. De ahí que

el Concilio deja atrás la concepción de una Iglesia fría, hierática e inamovible, basada en conceptos y verdades establecidas y permanentes y dogmáticas, para presentarnos una Iglesia más dinámica, eficaz y pastoral, con una dimensión itinerante, peregrina, sujeta a cambios y a revisión constante. (Álvarez-Suárez, 2010, p. 368)

De acuerdo con los alcances que se propuso el Vaticano II, "la constitución dogmática sobre la Iglesia, Lumen gentium, es considerada como el corazón del Concilio, la encarnación y el esquema central del que reciben sentido y medida todos los demás documentos" (Álvarez-Suárez, 2010, p. 325), lo que asegura una coherencia entre lo expresado y lo deseado por el Concilio, porque allí es donde reside la nueva eclesiología y, por ende, el epicentro de la renovación.

Aunque es evidente el cambio renovador de la Iglesia que se propuso el Concilio, es oportuno decir, junto con Bueno (1998), que "desde una perspectiva más serena hay que reconocer que el concilio produjo un gran impacto por la novedad eclesiológica que representaba. Su recepción y acogida no podía ser más que lenta y cargada de tensiones" (p. 17). Tensiones y lentitud que en los últimos años se han profundizado más a la par del deseo por una Iglesia sinodal, como si nos moviéramos entre dos extremos eclesiales, entre los que quieren el cambio y ser fieles al Vaticano II y los que buscan la conservación de lo establecido, pero que teológica, eclesial e históricamente carecen de sentido.

El camino hacia la sinodalidad en la Iglesia que inauguró el Concilio, y que ahora tiene un gran impulso en el magisterio de Francisco, en el caso del continente latinoamericano, ha contado con un buen respaldado por las conferencias episcopales (Celam) que han tenido lugar en este territorio (Medellín, Puebla, Santo Domingo y Aparecida) (Codina, 2008a, pp. 69-86). Cada una de ellas, desde su particularidad y realidad del momento histórico, ha respondido al llamado de renovación que la Iglesia necesita. Gracias a la comprensión que la Iglesia del continente ha hecho de sí misma como Pueblo de Dios, como sacramento de salvación, que debe estar del y al lado de los pobres, ha asumido la realidad del territorio como lugar teológico.

\section{Los desafíos para llegar a ser una Iglesia sinodal}

Aunque el impulso para consolidar una Iglesia sinodal goza de gran aceptación, es evidente, como lo señaló en 2018 la Comisión Teológica Internacional, que todavía persisten grandes desafíos, que es preciso superar, para hacer realidad el deseo de renovación del Vaticano II. Entre los puntos que seńala está "la revitalización de las estructuras sinodales", lo que a su juicio "se expresa en la respuesta a la gratuita llamada de Dios a vivir como su Pueblo que camina en la historia hacia la consumación del Reino" (n. $\left.{ }^{\circ} 103\right)$. La clave sin duda frente a este primer desafío es la comunión entre las iglesias, lo que no reduce el nivel de autonomía (si pudiera llamarse así), ni mucho menos la capacidad para que cada Iglesia particular responda evangélicamente a los desafíos que su realidad le presenta. 
Señala también la Comisión Teológica Internacional (2018) como gran desafío la conversión pastoral en los siguientes términos:

El gran desafío para la conversión pastoral que hoy se le presenta a la vida de la Iglesia es intensificar la mutua colaboración de todos en el testimonio evangelizador a partir de los dones y de los roles de cada uno, sin clericalizar a los laicos y sin secularizar a los clérigos, evitando en todo caso la tentación de "un excesivo clericalismo que mantiene a los fieles laicos al margen de las decisiones". (n. ${ }^{\circ} 104$ )

Coincide el planteamiento de la Comisión Teológica Internacional (2018) con lo ya dicho en dos frases por Bueno (1998), al sostener que el doble desafío del Vaticano II era sacar a la Iglesia de su eclesiocentrismo y jerarcología, para poder dar el paso a una Iglesia renovada y atenta a los signos de los tiempos. Y lo mismo ha dicho Codina (2008a) con ocasión de Aparecida, al señalar que el gran desafío era "pasar de una Iglesia conservadora a una Iglesia en estado de misión" (p. 85). Los desafíos mencionados pasan por lo que la misma Comisión Teológica Internacional y otros autores, incluido el papa Francisco, han llamado conversión pastoral, ya que sin ello no será posible hablar de una Iglesia sinodal. A nuestro juicio, surge un nuevo desafío diferente de los ya señalados: que cada bautizado se sienta parte de la Iglesia, se reconozca parte del Pueblo de Dios, asuma su lugar en ella y contribuya a la consolidación de una Iglesia sinodal. Se considera, entonces, que la conversión pastoral de la Iglesia pasa indudablemente por el trabajo pastoral de cada Iglesia particular. En la manera en que cada comunidad eclesial proyecte su trabajo pastoral, se podrá reflejar el camino de renovación que están siguiendo.

\section{La Arquidiócesis de Cali y su respuesta para ser una Iglesia sinodal}

Como se ha podido señalar hasta ahora, la Arquidiócesis de Cali ha realizado esfuerzos enormes por consolidar una Iglesia particular que responda a los deseos de renovación del Concilio Vaticano II. La manera en que la Iglesia de la ciudad ha respondido a los diferentes problemas que viven sus habitantes da cuenta de una Iglesia interesada en el bienestar de las personas (no solo en la necesidad sacramental y espiritual), lo que le ha exigido estar atenta a los signos de los tiempos, los mismos que la desafían a estar en salida, y le exigen seguir formando discípulos y misioneros que anuncien la buena noticia del Señor. Este recorrido por llegar a ser una Iglesia sinodal se expresa no solo en lo hecho hasta ahora, como ya se pudo indicar, también se observa en lo que se quiere seguir haciendo en los próximos cinco años con el plan pastoral 2019-2023.

Se observa claramente la apuesta por una Iglesia que quiere vivir la sinodalidad, precisamente su objetivo general: la presentación del plan que hace el arzobispo de la ciudad y los lineamientos o ejes transversales son evidencia de ello. En cuanto al objetivo general, se señala: "Propiciar en la Iglesia particular de Cali la evangelización Kerigmática en y desde la Eucaristía, de manera que lleve al encuentro personal con Cristo, a través de la misión permanente, sirviendo al desarrollo humano integral y solidario de todos" (Arquidiócesis de Cali, 2018, p. 4).

Este, además de incluir los elementos característicos de la eclesiología del Concilio y la eclesiología latinoamericana, da cuenta de la consciencia y la identidad que la Iglesia particular ha construido durante su andar en la ciudad, siempre atenta a servir al desarrollo humano integral y solidario de todos. Cabe resaltar, 
como lo ha expresado el Vaticano II, que la fuente de esa acción pastoral y evangelizadora de la Iglesia caleña está en la eucaristía, en que no solo se da el encuentro con el Señor resucitado, también la comunión de la comunidad, que hermana y moviliza a la misión. En el objetivo del plan pastoral, queda claro a qué eclesiología le apuesta la Arquidiócesis de Cali en su peregrinar en la ciudad.

En orden al este, la presentación que hace el arzobispo del plan pastoral confirma que la Arquidiócesis apuesta por la pirámide invertida de la que habló el papa Francisco. Destacan tres aspectos: identidad, interioridad y esponsalidad. Decir que la identidad de la Iglesia de Cali es ¡Ser cuerpo de Cristo! revela ante sus miembros que en esta Iglesia particular no hay distinción de creyentes, porque todos son miembros del cuerpo de Cristo, por tanto, todos están llamados a acoger el plan pastoral (y la sinodalidad que subyace). Luego, está la interioridad, sobre la cual expresa que es el rasgo característico de la Arquidiócesis: ser una Iglesia al servicio de todos. Después está la esponsalidad, que se describe como la espiritualidad eucarística a la que han de llegar todos en esta Iglesia particular.

Tras el abordaje de lo que podría llamarse valores identitarios y programáticos, el arzobispo aborda dos temas centrarles de la sinodalidad: la superación de la estructura piramidal en la Arquidiócesis y la conversión pastoral. De la primera confirma que en la Iglesia existe un cuerpo de servidores y no una estructura piramidal dominante; al respecto, indica:

La Asamblea Parroquial de servidores o Agentes Pastorales, identificará que el Párroco es un servidor con otros servidores, que reconoce su carisma o gracia propia como capacidad para reconocer, acompañar y regular los carismas de todos los creyentes y ayudarles a ponerlos al servicio de la comunidad eclesial y de la sociedad humana. (Arquidiócesis de Cali, 2018, pp. 8-9)

Como era de esperarse, el mensaje del arzobispo se dirige a la comunidad parroquial (asamblea de servidores), lugar natural donde participan los bautizados y donde también es preciso que los cambios que exige la sinodalidad como modo de ser de la Iglesia se lleven a cabo en primera instancia. Al presentar al sacerdote como un servidor entre los servidores, el plan pastoral presenta un desafío a la comunidad: redescubrir el papel del sacerdote; esta nueva comprensión pasa sin duda por la buena formación que reciben todos los bautizados. ${ }^{12}$ Coincide este planteamiento del arzobispo con lo dicho en la primera parte, al afirmar que la identidad de la Iglesia particular de Cali es "ser cuerpo de Cristo", y no una Iglesia jerárquica y mucho menos piramidal.

Después de reubicar la posición del sacerdote en la comunidad, servidor entre los servidores, en una apuesta hacia la sinodalidad, el arzobispo otorga todo el reconocimiento y centralidad a la asamblea. Así lo expresa en la presentación del documento: "Con la Asamblea como órgano sistemático de la comunión y comunidad parroquial, del servicio a los fieles y a la sociedad dentro de la cual viven como levadura en la masa, como sabor y luz de Cristo, se iniciará todo el proceso del 'plan quinquenal 2019-2023'” (Arquidiócesis de Cali, 2018, p. 9). Es sumamente interesante que se afirme que el plan pastoral tiene

12 Es preciso destacar los diferentes procesos de formación que la Arquidiócesis ha tenido desde hace décadas, en especial la formación catequística y la preparación para la misión, precisamente desde hace casi diez años se cuenta con el Centro de Evangelización Arquidiocesana, una entidad que aglutina todos los procesos de formación de laicos comprometidos en la ciudad. 
como punto de partida la transformación de la concepción de la comunidad parroquial (la asamblea) y, por tanto, no deje exclusivamente su desarrollo únicamente en manos de los sacerdotes. Es decir, todos los bautizados de esta Iglesia particular trabajarán juntos por la comunidad y la sociedad.

Por otra parte, cabe señalar que el arzobispo es consciente de que todo este proceso de transformación de la vida parroquial pasa no solo por la aceptación y disposición de la comunidad, sino también por la comprensión del sacerdote respecto de lo que implica la sinodalidad. De ahí que se indique con respecto a este cambio que el primer y necesario paso que se requiere es la "'conversión del pastor', superando el clericalismo, el enfoque meramente cultual y devocional, todo autoritarismo y tendencia al abuso que, en tantas y dolorosas formas, tenemos que erradicar" (Arquidiócesis de Cali, 2018, pp. 9-10). Coincide en este aspecto el arzobispo con la Comisión Teológica Internacional (2018, n. $\left.{ }^{\circ} 104\right)$, que anota que sin conversión del clero no será posible la renovación que la Iglesia necesita para salir de la pastoral de conservación que ya poco o nada dice a los mismos creyentes y a la sociedad.

Valorar la dignidad de todos los bautizados (miembros todos del cuerpo de Cristo), reconocer en cada miembro de la comunidad un servidor sin distingo de posiciones y ministerios, reconfigurar la asamblea como órgano sistemático de la comunión y comunidad parroquial e invitar a la conversión a los pastores son rasgos propios de una Iglesia que va en salida del modelo jerárquico y piramidal, y busca convertirse para llegar a ser una Iglesia sinodal. Lo que sigue ahora es la conversión pastoral.

Si como sostiene Juan Mena (2017), que "solo una iglesia en camino de conversión puede ser una iglesia misionera” (p. 384), es posible decir que, con el plan pastoral 2019-2023, la Iglesia particular de Cali está en camino de conversión, lo que de cierto posibilita la tan anhelada conversión pastoral, que no es más que salir de los viejos esquemas para recuperar su identidad misionera. Con ocasión de este segundo desafío eclesial, respecto de la evangelización en la ciudad, expresa el plan pastoral:

Desde la asamblea, debidamente conformada y motivada, se podrá iniciar o hacer un seguimiento a todos los sectores del territorio parroquial, a los diversos sectores humanos, generacionales y situacionales, dando inicio a procesos de primer y nuevo anuncio del Evangelio. Iniciación cristiana para adultos (sin descuidar la niñez y los adolescentes), la participación en pequeñas comunidades de discipulado y misión permanente, procurando la construcción del tejido familiar, de tejido social, de convivencia y cuidado de la casa común en el territorio parroquial. (Arquidiócesis de Cali, 2018, p. 10)

Entender la evangelización desde estos referentes, la Asamblea como centro, la presencia en todos los sectores de la parroquia, la cercanía con los diferentes grupos humanos, la revitalización del primer anuncio, la formación para la misión, la construcción de tejido social y el cuidado de la casa común, pone en evidencia a una Iglesia que está saliendo de la estructura piramidal y de la pastoral litúrgica-cultual (pastoral de conservación), porque quiere salir de sí misma, para responder a los desafíos que la realidad le demanda (pastoral misionera). La comprensión de la evangelización que hace la Arquidiócesis en su plan pastoral da cuenta de lo que pide la reforma misionera de la Iglesia en clave sinodal: "la reforma comunitaria, la reforma de iniciación, la reforma ministerial y la reforma de las prácticas evangelizadoras" (Mena, 2017, p. 396). Y aunque en la práctica no resulte ser una tarea sencilla responder acertadamente al plan de evangelización que concibe la Arquidiócesis, es evidente el deseo de seguir apostando por la renovación de la Iglesia. 
$\mathrm{Al}$ mismo tiempo, como la Iglesia particular de Cali no quiere renunciar a su identidad, sirviendo al desarrollo humano integral y solidario de todos, para la Arquidiócesis, la primera incidencia de los procesos de evangelización es la reconciliación (Arquidiócesis de Cali, 2018, p. 11). La dura realidad histórica de conflicto y violencia en que se ha visto atrapado el país, y en particular el suroccidente colombiano, requiere una respuesta asertiva de la Iglesia en este aspecto, al que también se debe unir la apuesta por el perdón como don de Dios que libera, sana y renueva, de tal suerte que se renuncie a la venganza y el odio, motores que avivan la violencia en nuestra sociedad.

En razón de la dura realidad local y regional que afronta esta porción del país, la Iglesia particular de Cali, en proceso de conversión eclesial y pastoral, asume el desafío misionero y pastoral de la reconciliación y el perdón en la sociedad como aspecto central de su quehacer evangelizador, pues "el Amor de Cristo nos apremia’ ante la enorme degradación social y corrupción institucional que el narcotráfico, la sed de dinero y el desbordamiento de los instintos, están causando en todos" (Arquidiócesis de Cali, 2018, p. 11). Así las cosas, la conversión pastoral en la Arquidiócesis se evidencia en la comprensión teológica que se logra hacer de la realidad, al ver lo que ocurre en la ciudad y la región como un signo de los tiempos, como un lugar teológico en el que Dios se manifiesta.

Finalmente, el plan pastoral 2019-2023 de la Arquidiócesis de Cali apunta a que todo lo proyectado permita a la Iglesia particular empezar el itinerario hacia la sinodalidad. Pone su esperanza en las "casitas católicas', donde las familias en actitud misionera permanente sean testimonio de Cristo. Ir por el camino sinodal es para la Arquidiócesis fruto del "aprendizaje de caminar juntos con jesús" (Arquidiócesis de Cali, 2018, p. 12). Por tanto, "el aprendizaje sinodal, que deberá llevar a cada comunidad parroquial a constituirse como una realidad con vida y vitalidad comunitaria, sin parar mientes en límites y limitaciones, y generando una cultura de solidaridad interna eclesial en arciprestazgos y zonas pastorales" (Arquidiócesis de Cali, 2018, p. 12). Si llegar a ser una Iglesia sinodal no es algo sencillo, porque "la sinodalidad implica actitudes adecuadas, especiales formas de proceder, determinadas dinámicas relacionales, precisas garantías jurídicas” (Schickendantz, 2017, p. 40), es posible afirmar que el plan pastoral es esa garantía que la Iglesia particular de Cali necesita para responder al deseo de Dios. Si la sinodalidad es fruto del cambio eclesiológico que propuso el Concilio Vaticano II, cambio que estuvo sustentando en la necesidad imperante de volver a las fuentes, entonces el punto de partida de esta reforma implica asumir como centro el proceso evangelizador y pastoral el Evangelio, de ahí que "se pone el acento sobre la vuelta a lo esencial: un retorno al Evangelio" (Schickendantz, 2017, p. 37). En el caso de la Iglesia particular de Cali, es el Evangelio mismo que sigue inspirando y animando en la conversión a una nueva manera de ser Iglesia, gracias al papel preponderante que ha tenido la Sagrada Escritura en las prácticas pastorales de la Arquidiócesis.

\section{Conclusiones}

El camino hacia la sinodalidad no será fácil para la Iglesia universal, porque la superación milenaria de jerarquía y poder está en medio, y en algunos ambientes no existe la mejor actitud frente al cambio. Sin embargo, la apuesta no puede decaer "pues la sinodalidad es lo que Dios quiere para la Iglesia del tercer milenio", como bien lo dijo el papa Francisco (2015) en el Discurso de la conmemoración de los 50 años de la institución del sínodo de los obispos. En ese orden de ideas, y ante la dificultad que esto puede traer para la Iglesia y para quienes lideran esta vuelta a los orígenes, es fundamental conocer, valorar y respaldar 
todas las iniciativas eclesiales que transiten, entre aciertos y desaciertos, hacia la sinodalidad. En ese sentido, es importante para la Iglesia destacar los aciertos que cada Iglesia particular va teniendo en este aspecto, tal es el caso de la Arquidiócesis de Cali.

Aunque no es posible decir que la Iglesia particular de Cali ha interiorizado totalmente lo que es una Iglesia sinodal (el plan pastoral todavía está en ejecución), es importante apoyar la apuesta que está naciendo. En favor está la manera en que la Iglesia caleña ha hecho presencia en la ciudad a través de su doble acción pastoral, lo que ha configurado un modo de ser Iglesia más cercana a lo querido por el Vaticano II. Con su presencia y acción pastoral, la Iglesia caleña ha comprendido lo que significa ser sacramento de salvación. Por un lado, atendiendo la función litúrgico-sacramental y catequética, y por otro, asumiendo un compromiso evangélico con la realidad social de la ciudad, estando atenta a los signos que tienen lugar. Poco a poco, en ese proceso de salida de sí misma para ir al Pueblo de Dios que sufre espiritual, moral y materialmente, se va configurando como esperanza de salvación en la ciudad, desde el servicio y la solidaridad, y no desde el poder y la autoridad. ${ }^{13}$

Finalmente, llamar la atención sobre lo que todavía se puede hacer (porque no es evidente en la revisión realizada) con respecto a los cambios estructurales que esta apuesta requiere. Porque la sinodalidad no es una moda o un discurso, "es el deseo de Dios", de ahí que se requieren cambios estructurales y de forma que no pueden obviarse, porque, de no hacerlos, aunque se hable de sinodalidad, no se transita hacia esta. Aquí es preciso señalar la necesidad de contar con un mecanismo eclesial que pueda verificar la creación y buena funcionalidad de las asambleas eclesiales en las parroquias. Esta apuesta no puede quedar a criterio del sacerdote. Por la gran posibilidad que hay aquí de entrar en el espíritu sinodal, es preciso que las asambleas parroquiales se consoliden espacio de comunión y participación en que "los laicos deben participar del discernimiento, la toma de decisiones, la planificación y la ejecución” (Celam, 2007, n.o 371).

La Iglesia particular de Cali, en su camino como Iglesia Pueblo de Dios y ahora hacia una Iglesia sinodal, tiene grandes retos por superar en los próximos años, entre ellos la superación del clericalismo y la no clericalización de los laicos, como lo ha señalado el mismo arzobispo. Esperamos para la Arquidiócesis de Cali, como lo expresó la Comisión Teológica Internacional, que "ser verdaderamente 'sinodal' (sea) avanzar en armonía bajo el impulso del Espíritu" (n. ${ }^{\circ} 48$ ).

\section{Referencias}

Abadía Quintero, C. y Echeverry Pérez, A. J. (2015). Historia de la Iglesia católica en el Valle del Cauca (1927-1985). Fundación Universitaria Católica Lumen gentium.

Agudelo Grajales, D. (2012). La Iglesia católica en Cali durante el siglo XX: Una presencia viva y desconcertante. En W. F. Jiménez Hernández (coord.), Historia de Cali siglo XX. Vol. 3: Cali en la primera mitad del siglo XX: Mentalidades y sensibilidad (pp. 122-143). Universidad del Valle.

13 Esta expresión recoge el título de la ponencia presentada en el Congreso Internacional "Hecho religioso en América Latina”, realizado entre el 12 y 16 de abril de 2021, organizado por la Universidad del Valle. 
Alberigo, G. (2015). Breve historia del Concilio Vaticano II (1959-1965) (2.a ed.). Sígueme.

Alberigo, G. y Jossua, J.-P. (eds.) (1987). La recepción del Concilio Vaticano II. Cristiandad.

Álvarez-Suárez, A. (2010). Repensando la Iglesia como Pueblo de Dios desde la Lumen gentium del Vaticano II. Teresianum: Rivista della Pontificia Facoltà Teologica e del Pontificio Istituto di Spiritualità, 61(2), 325-370. https://dialnet.unirioja.es/servlet/articulo?codigo $=536394$

Arquidiócesis de Cali. (1964). Informe al nuncio apostólico.

Arquidiócesis de Cali. (1976). Departamento de Diseño.

Arquidiócesis de Cali. (1985). Plan de Pastoral. Arquidiócesis de Cali. 75 años. Boletín Participación.

Arquidiócesis de Cali. (1989). Plan de Pastoral 1990-1992. Boletín participación.

Arquidiócesis de Cali. (2011). Sinodo 2010. 2 Actas y sintesis.

Arquidiócesis de Cali. (2011). Sinodo 2010. Primer informe.

Arquidiócesis de Cali. (2014). El descubrir pastoral. 50 años de la Arquidiócesis de Cali como sede metropolitana.

Arquidiócesis de Cali. (2018). Plan de Pastoral 2019-2023.

Arquidiócesis de Cali. (2019). Linea base para un balance social de la Arquidiócesis de Cali.

Azcuy, V. R. (2013). La recepción del Concilio Vaticano II en el pueblo de Dios: Testimonios sobre la renovación desde las formas de vida. Teologia, 50(112), 203-249. https://repositorio.uca.edu.ar/handle/123456789/7173

Azcuy, V. R. (2019). El discernimiento teológico-pastoral de los signos de los tiempos en Medellín: Lectura interpretativa de los grandes temas de la II Conferencia. Teología, 49(107), 125-150. https://repositorio.uca. edu.ar/handle/123456789/7577

Bueno, E. (1998). Eclesiología. BAC.

Codina, V. (2008a). Eclesiología de Aparecida. Revista Iberoamericana de Teología, 6, 69-86. https://dialnet.unirioja. es/servlet/articulo?codigo $=5559991$

Codina, V. (2008b). Para comprender la eclesiología desde América Latina. Verbo Divino.

Comisión Económica para América Latina y el Caribe. (s. f.). Acerca de la Cepal. https://www.cepal.org/es/acerca

Comisión Teológica Internacional. Vaticano II. La sinodalidad en la vida y en la misión de la Iglesia. Marzo 2 de 2018. http://www.vatican.va/roman_curia/congregations/cfaith/cti_documents/rc_cti_20180302_sinodalita_ sp.html

Conferencia Episcopal de Colombia. (1985). Mensaje pastoral 1985 de la XLIV Asamblea Plenaria Extraordinaria del Episcopado Colombiano (23 al 26 de septiembre de 1985).

Consejo Episcopal Latinoamericano. (1968). II Conferencia General del Episcopado Latinoamericano. http://web. celam.org/conferencias-generales/

Consejo Episcopal Latinoamericano. (1979). III Conferencia General del Episcopado Latinoamericano. http://web. celam.org/conferencias-generales/

Consejo Episcopal Latinoamericano. (1992). IV Conferencia General del Episcopado Latinoamericano y del Caribe. http://web.celam.org/conferencias-generales/ 
Consejo Episcopal Latinoamericano. (2007). V Conferencia General del Episcopado Latinoamericano y del Caribe. http://web.celam.org/conferencias-generales/

Costadoat, J. (2020). La formación teológica en América Latina antes del Concilio. Estudios Eclesiásticos, 95(373), 441-455. https://doi.org/10.14422/ee.v95.i373.y2020.006

De Roux, R. (2012). De la nación católica a la república pluricultural en América Latina: Algunas consideraciones históricas. Memorias: Revista Digital de Historia y Arqueología desde El Caribe, 16(1), 1-35. https://www. redalyc.org/articulo.oa?id=85528618002

De Roux, R. (2014). La romanización de la Iglesia católica en América Latina: Una estrategia de larga duración. Pro-Posiçôes, 25(1), 31-54. http://www.scielo.br/scielo.php?script=sci_arttext\&pid=S0103

Echeverry Pérez, A. J. y Abadía Quintero, C. (2010). Aproximación histórica a la Diócesis de Cali. Universidad del Valle.

Francisco. Vaticano II. Conmemoración del 50 aniversario de la institución del sínodo de los obispos Discurso del Santo Padre Francisco. Octubre 17 de 2015. http://www.vatican.va/content/francesco/es/speeches/2015/ october/documents/papa-francesco_20151017_50-anniversario-sinodo.html

Francisco. Vaticano II. Exhortación apostólica Evangelii gaudium. Noviembre 24 de 2013. http://www.vatican.va/ content/francesco/es/apost_exhortations/documents/papa-francesco_esortazione-ap_20131124_evangeliigaudium.html

Iberico Ruiz, R. (2018). La eclesiología de Medellín: Memoria y desafío para la Iglesia de hoy. Páginas: Centro de Estudios y Publicaciones, 250.

Madrigal Terrazas, S. (2005). Glosas marginales de K. Rahner sobre el Concilio Vaticano II. Estudios Eclesiásticos, 80(313), 339-389. https://revistas.comillas.edu/index.php/estudioseclesiasticos/article/view/9747

Madrigal Terrazas, S. (2015). El concilio Vaticano II: remembranza y actualización. Teología, 117, 131-163. https:// repositorio.comillas.edu/xmlui/handle/11531/17527

Mena Hernández, J. M. (2017). La conversión pastoral y misionera desde la perspectiva de la complejidad. Salmanticensis, 64(3), 371-401.

Mendoza Carmona, D. S. (2020). Un modelo eclesiológico para América Latina. Antecedentes tipológicos y particularidades. Caminos, 1(8), 60-64. https://revistas.uniclaretiana.edu.co/index.php/Camino/article/ view/234

Montoya Flórez, E. (2012). Isaías Duarte Cancino: Sangre de profetas. San Pablo.

Pablo Obispo. Concilio Vaticano II. Constitución dogmática Dei Verbum sobre la divina Revelación. Noviembre 18 de 1965.

Pablo Obispo. Concilio Vaticano II. Constitución dogmática sobre la Iglesia Lumen gentium. Noviembre 21 de 1964. https://www.vatican.va/archive/hist_councils/ii_vatican_council/documents/vat-ii_const_19641121_lumengentium_sp.html

Pablo Obispo. Concilio Vaticano II. Constitución pastoral Gaudium et spes sobre la Iglesia en el mundo. Diciembre 7de 1965. https://www.vatican.va/archive/hist_councils/ii_vatican_council/documents/vat-ii_const_19651207_ gaudium-et-spes_sp.html

Parra, A. (1979). La eclesiología de comunión en Puebla. Theologica Xaveriana, 29, 117-136. https://revistas.javeriana. edu.co/index.php/teoxaveriana/article/view/26555/22399 
Polanco, R. (2020). Necesidad de una perspectiva "polar" para recuperar teológica y estructuralmente las iglesias locales. Estudios Eclesiásticos, 95(372), 31-68. https://doi.org/10.14422/ee.v95.i372.y2020.002

Richi-Alberti, G. (2013). Una relectura de la constitución Lumen gentium a cincuenta años de la apertura del Concilio Vaticano II. Carthaginensia: Revista de Estudios e Investigación, 29(55), 53-70. https://dialnet.unirioja. es/servlet/articulo?codigo $=4373557$

Schickendantz, C. F. (2012). Único ejemplo de una recepción continental del Vaticano II: Convocatoria, desarrollo y estatuto eclesial-jurídico de la Conferencia de Medellín (1968). Teología, 108, 25-53. https://repositorio. uca.edu.ar/handle/123456789/6948

Schickendantz, C. F. (2017). La reforma de la Iglesia en clave sinodal: Una agenda compleja y articulada. Teología y Vida, 58(1), 35-60. http://dx.doi.org/10.4067/S0049-34492017000100002

Tolmos Méndez, C. A. (2018). La recepción del Concilio Vaticano II por parte del clero de la Arquidiócesis de Cali (1962-1979) [tesis de maestría, Universidad del Valle]. http://hdl.handle.net/10893/14265

Vela, J. (2002). El camino de la planeación pastoral. Theologica Xaveriana, 142. https://revistas.javeriana.edu.co/ index.php/teoxaveriana/article/view/20915/16248 